\title{
Impact of Performance-Based Financing on Health Facilities Performance in Family Planning
}

\author{
Agonnoude T. Maurice, ${ }^{1, *}$, Houeto S. David ${ }^{1}$, Sambieni N. Emmanuel ${ }^{2}$, Adoukonou T. Thierry A ${ }^{1}$, \\ Aguessy Constant $^{3}$

\begin{abstract}
${ }^{1}$ National School of Public Health and Epidemiology Surveillance (ENATSE), University of Parakou, Benin
${ }^{3}$ Department of English, Letters, Faculty of Arts, and Human Sciences (FLASH), University of Parakou, Benin
\end{abstract} \\ ${ }^{2}$ Department of Anthropology Sociology, Faculty of Arts and Human Sciences (FLASH), University of Parakou, Benin
}

Received September 15, 2019; Revised November 26, 2019; Accepted December 4, 2019

Copyright $\odot 2020$ by authors, all rights reserved. Authors agree that this article remains permanently open access under the terms of the Creative Commons Attribution License 4.0 International License

\begin{abstract}
Toward the end of that scaling up of performance-based financing (PBF) started in Benin since 2015, it's important to realize whether the impacts in terms of performance improvement of health facilities (HFs) will still be confirmed or not, especially as far as family planning (FP) is concerned. A longitudinal retrospective study covered by the period of 14 quarters of a year (Q1 2014 to Q2 2017), was conducted including all public and private functional HFs of the two health district. The outcome variable (performance of HFs in FP) was the increase rates of new acceptance for any modern contraceptive method through the study period. The independent variables were the quality of the structure, the quality of the process and the context. A linear regression model was adjusted to find out the explanatory variable of the performance; the significance threshold was 5\%. 55 HFs participated to the study. There was no improvement in supplying process of FP services $(\mathrm{p}=0.308)$. There was no improvement in both trained staff $(\mathrm{p}=0.67)$ and midwifery staff ( $\mathrm{p}=0.75$ ); however, there was a significant improvement in the rest of the structure at the risk of $10 \%$ $(\mathrm{p}=0.063)$ and the performance in FP $(\mathrm{p}<0.001)$. In multivariate analysis, the evolution of the structure was the only explanatory variable $(p=0.029)$ of HFs performance in $\mathrm{FP}$; in rural areas, the structure-process interaction $(\mathrm{p}=0.038)$ was the explanatory variable of HFs performance in FP, whereas in suburban and urban areas, the models were not significant. PBF should act not only on the structures but also on the processes of supplying services, taking into account the context.
\end{abstract}

Keywords Family Planning, PBF, Health Care Quality, Health Care Structure, Health Care Process, Borgou, Benin

\section{Introduction}

According to Canavan et al [1], Performance Based Financing (PBF) is a form of financing based on the assumption that the linking of motivations to performance would contribute to improving the accessibility, the quality and the equity in provision of health services. Researchers, in fact, while recognize the importance of this system, suggest a particular caution to its conception implementation and evaluation. That is why this study was launched to evaluate the impact of this system of financing on health facilities performance about PBF in family planning domain in Benin.

\section{Background}

In Benin, the PBF has started in its practical phase since 2012 with two experiments: one financed by the World Bank in eight health districts [2, 3] and the second one in five other health districts in the administrative departments of Mono, Couffo and Donga, with the support of the Belgian Technical Co-operation [4]. The basic idea was to strengthen the performance of the health system mainly through [2]: (i) the implementation of the contractual approach (ii) the implementation of the quality improvement process of health care and services; and (iii) the introduction of financial incentives commensurate with the provision of quality of care and services to the population. The results of these different experiments were conclusive especially as far as the improvement of the quality of care is concerned. This motivated the decision to scale up PBF to other health districts in the country since June 2015. Therefore, since the conditions of the pilot experiments are not the same as the one of the scaling up, it was important two years after the beginning of this generalization to see the impact of PBF on the 
performance of health facilities in terms of improvement of the quantity and quality of services offered to the population. This took place in two health districts of Borgou administrative departments, namely Parakou-N'Dali (PN) district and Nikki-Kalalé-Pèrèrè (NKP) district.

The activities included in this funding are part of the so-called High Impact Intervention Package, which concerns maternal and child health activities, and priority diseases (malaria, HIV/AIDS and tuberculosis). These activities are grouped into a minimum package of activities (MPA) for peripheral health facilities. Among the maternal and child health activities, there is a family planning services. Indeed, no personal, family or national development is possible if there is not the mastery of fertility and therefore of population growth. For instance, at the global level, Sustainable Development Goal Five (SDG 5) emphasizes universal access to sexual and reproductive health services, including family planning services; however, this is not yet a reality because in 2015, the contraceptive prevalence rate in Eastern and Southern Africa was $38.6 \%$, and only $17.6 \%$ in West and Central Africa [5].

More importantly in Benin, fertility remains high as well as the level of variation of contraceptive use prevalence: $13 \%$ of the prevalence of modern contraceptive use in 2017 among women aged 15-49 and $26.5 \%$ of the satisfied demand [6]. In the department of Borgou, especially the 2 health districts concerned by this study, the total fertility rate was 5.3 children per woman (4th department in Benin) and the unsatisfied demand for FP was 27\% (8th department in Benin)[7]. For this reason, the National Program of Health Development has chosen to intensify family planning services in order to reduce maternal and infant-juvenile mortality.

The objective of this study is to analyze the impact of PBF on HFs performance concerning family planning in $\mathrm{PN}$ and NKP health district, via the quality of the structure and the process of offering these services as well as the possible link between performance and the quality of the process, on the one hand, and the structure on the other.

\section{Literature Review}

PBF is a financing reform of health systems consistent with free market (or liberal) economy. Even if recently introduced in Benin, this system exists since some years on Africa. Blanchett (2003) cited by Canavan A. et al. [1] stated that its impact depended of demographic, organizational characteristics of healthcare providers including activities volume, local competitive environment, wage grants acceptation by employees and confidence of actors in the appropriateness of this mechanism of financing. In this brief review will try to examine successively the potential impacts of PBF system, the successful factors, the results measure and some impediment factors.

\subsection{Had PBF Has Any Impact and What Could Be These Impacts in General?}

According to Loevinsohn B. and A. [8], PBF has some interesting features such as: - a special focus on measurable results if contracts set out objectively measurable results in the short, medium or long term ; - a constraint that prevent States to use resources efficiently; a high degree of flexibility and good private sector morality in improving services ; - a greater managerial autonomy and decentralized decision making and, finally to the ability of States occasion to focus on their traditional roles in planning, standard-setting, financing, regulation and other public health functions. After analyzing the PBF experiences of five African countries, Toonen, Canavan, Vergeer, and Elovainio [9], concluded that given confounding contextual factors and the reliability of data available, PBF could be a tool of continuous improvement of quality and productivity in the health sector compared to the traditional approaches to input financing. This is why, for example, Soeters R., Peerenboom P-B., Mushagalusa, and C [10] found in Democratic Republic of Congo that the introduction of PBF subsidies led to a reduction in users' fees and better quality healthcare compared to health facilities without PBF subsidies.

\subsection{Associated Factors to Successful PBF}

For Meessen, Soucat, and Sekabaraga [11], the performance-based funding could catalyze comprehensive reforms and help address structural problems related to public health services, such as low responsiveness, inefficiency and injustice. They said that the speed of the PBF movement in Africa has led to the belief that it could transform the public sectors of low-income countries in depth. The PBF was a promising mechanism for boosting performance in health facilities, but it is dependent on simultaneous investment in the resources and management capacity that are essential for success and sustainability. It also seems that there are no procedures for introducing CVT in the public health sector as in Benin, but what was crucial seems to be a strengthened and autonomous management system in health establishments. In fact, according to Soeters R., Habineza C., and P-B [12] (2006, p. 887), "respecting the self-management of service providers is important to encourage their entrepreneurial spirit". Another important factor in success was the motivation of suppliers to change their behaviour to achieve organizational goals. With this in mind, the researchers found that the management system could be a stimulus for the training activities of healthcare providers, which could lead to improved performance and the intrinsic motivation of the actors (staff motivation was 
positively correlated to the availability of training opportunities). The link between the PBF and extrinsic motivation was more direct and straightforward than with intrinsic motivation. Different approaches are distinguished by the separation between financial motivations towards organizations and those towards individuals; external resources of organizations could be used to motivate staff according to the link to performance internal motivation system. The PBF system in Benin had solved the system of predetermination of subsidies, a system of distribution between individual suppliers and organizations. Oxman and Fretheim[13] (2009), in their systematic review of the effectiveness of the PBF in achieving the Millennium Development Goals, concluded that financial incentives are effective in the short term in achieving simple and well-defined behavioural goals. Several improvements in space have been observed among NGOs and public health providers in Haiti and Rwanda: (i) the need for more flexibility and autonomy in the management of their project; (ii) increased opportunities for professional development and capacity-building; (iii) high expectations for less frequent and better reporting; and (iv) staff competencies to be more innovative and to lead with a high degree of motivation to sustainable results. Thus, the creation of a more autonomous and supportive environment, combined with financial motivation for targets, has proven to be a potential increase in quantitative and qualitative outcomes [1]. Loevinsohn B. and A. [8] confirmed that successful approaches were related to maximizing contractors autonomy, focusing on outputs and outcomes that require fair attention in the monitoring and evaluation process, setting a target population of no less than 500,000 beneficiaries to allow economies of scale and reduce the burden of contract management.

\subsection{How Do We Measure Results?}

The enhancements have evolved through trials - errors testing without success, as noted by Eichler, Auxila and Pollock [14], while Meessen, Musango, Kashala, and Lemlin [15] have suggested that investing in PBF can lead to positive results, but that it would not be perceived as an attempt to revitalize the flawed public health sector. Trivial evidence and well-founded results have shown that the PBF has played an important role in large institutions. This has resulted in increased motivation of managers and service providers, innovative approaches and greater accountability. Changes in caregiver behaviours have been reported in the scientific literature, but community attitudes and behaviours have not been amplified in relation to community perceptions and confidence in the CPF system [1]. For Dubbledam (2007) cited in Canavan A. et al. [1], it is not possible to measure impact indicators (mortality, prevalence) at the facility level, but it would be more appropriate to focus on process indicators and make pre-and post-Trend comparisons of these PBF interventions. Fretheim, Witter, Lindahl and Olsen [16] added that if randomized controlled trials were not feasible, other stronger models would be considered. For example, one of the most feasible options would be to have continuous time series with data collected at regular intervals in pre-and post-intervention (e.g. one year before and one year after intervention), but data quality requires good quality of routine data from health facilities and other reliable sources that are not always available in low-income countries.

Would PBF be a panacea for all health sectors problems? What were the pitfalls and potential difficulties?

Several authors [1, 8] have suggested that the PBF was not a panacea but only one approach among others to help healthcare providers improve health care delivery. The difficulties were multiple and related to: - the impossibility in large-scale contracts to have an impact country level: contracts more expensive than public sector offer because of transactions and management costs: - increased inequality in the supply of healthcare: -no sustainable contractualization system despite its effectiveness [8]. Meessen et al (2006) cited by Canavan A. et al. [1] undertook a pre and posttest study in 15 health centres in Butare province, Rwanda, in 2003. They added a caveat about PBF, indicating that caregivers were inclined to focus on subsidized health services while neglecting all others (reproductive health services/transmissible diseases); the risks under-reporting or over-reporting were also inherent to the system as majority of the majority of studies were not case studies involving triangulation data with data from household health studies. Others risks related to the targeted motivations, compromised quality of healthcare in order to achieve consumption targets. Several approaches have been taken to overcome these potential risks. Based on these difficulties or pitfalls, authors such as Fretheim et al. [16] criticized the PBF as merely a vehicle for an idea of privatizing public health services with a further withdrawal of state funding according to neoliberal ideology. For advocates, such contracts could be one way for States, to maintain the relevance of health services funding. Others pointed out that the methodological weakness of the available studies did not allow a clear conclusion to be draw about the effectiveness of contract financing. For Oxman and Fretheim [17], the PBF itself is a set interventions and it will be difficult, if not impossible to dissociate the effects of increased funding, technical support, training, new resources for management structures and monitoring system.

After this brief literature review, it will be important to highlight some of the particularities of our context that justify this study. In Benin, the PBF was mostly about public health care providers, while one of the attractive features of the PBF was the flexibility and morality of the private sector to improve services. Managerial autonomy and decentralized decision-making were essential for 
success, while in Benin the autonomy of the public health sector was not a reality; no significant investment has been made in human resources in Benin, while a simultaneous investment in resources and management capacity is essential for success and sustainability. Our measure of impact was relative to the productivity of health care facilities, while the authors focused on improving the quality of health care. We assume that an improvement in quality will be followed, in the short or medium term, by an increase in demand and then by an increase in productivity.

\section{Methods}

We conducted a longitudinal retrospective study in order to analyse the influence of the structures, processes and contexts of care provision in health facilities of the Parakou-N'Dali and Nikki-Kalalé-Pèrèrè health district exposed to PBF. A total of 52 Health Facilities functional from the beginning to the end of the experiment were included. The outcome variable was the number of new acceptance for any modern contraceptive method analyzed in terms of the increased rates through the study period. The main independent variables concerned the structures defined as a set of material, human and financial resources necessary to offer Family Planning services as defined in the Benin PBF quality grid. Other independent explanatory variables included processes defined as application of the best procedures to Family Planning services production (including specific training, supply planning, supervision, compliance with procedures and care protocols) and context (the environment of the HFs and their level on the health pyramid). Data were collected using a routine data sheet (from 2014 to 2015). Quantitative and qualitative PBF data from Q3 of 2015 were also collected. The increase rates of new acceptance were calculated over the period of the quarters before and after the beginning of the PBF. They were compared using the matched means t-test. Similarly, the structural and process quality indicators before and at the end of the experiment were calculated for means comparison using the same procedure. Finally, a linear regression model taking as outcome variable the increase rate of new acceptance over the entire duration of the experiment was adjusted. In our modelling strategy, we performed bivariate analyses to detect independent variables with potential to influence the outcome variable as well as those that could be linked together to avoid collinearities in the model. The significant threshold is $5 \%$.

\section{Results}

Table 1 shows the distribution of health facilities according to contextual variables.

Table 1. Contextual variables

\begin{tabular}{|l|c|c|}
\hline \multirow{2}{*}{ Variables and modalities } & \multicolumn{2}{|c|}{ Frequency } \\
\cline { 2 - 3 } & $\mathrm{N}$ & $\%$ \\
\hline Area of the health facility & \multicolumn{2}{|c|}{55} \\
\hline - Rural & 42 & 76.4 \\
\hline$\bullet \quad$ Semi-urban & 7 & 12.7 \\
\hline - Urban & 6 & 10.9 \\
\hline Health facility's level on the pyramid & & \\
\hline$\bullet \quad$ Dispensary or Isolated Maternity & 20 & 36.4 \\
\hline - HF of municipal borough & 24 & 43.6 \\
\hline - Commune health centre & 8 & 14.5 \\
\hline Other & 3 & 5.5 \\
\hline
\end{tabular}

More than $3 / 4$ of health facilities evolved in rural areas, more than $7 / 10$ of them were isolated clinics or maternity or HF of municipal borough. Autonomy has been removed from variables as all the health facilities see not to be autonomous.

\subsection{Health Facilities' Performance in Family Planning}

Figure 1 shows the evolution of the absolute number of new acceptance for family planning all methods combined in both PN and NKP health district. There is a saw-tooth evolution in the two districts even though at Parakou-N'Dali districts the trend after the beginning of PBF is clearly above that before.

Tables 2 and 3 showed the evolution of human resources, structure and process in the two health district. 


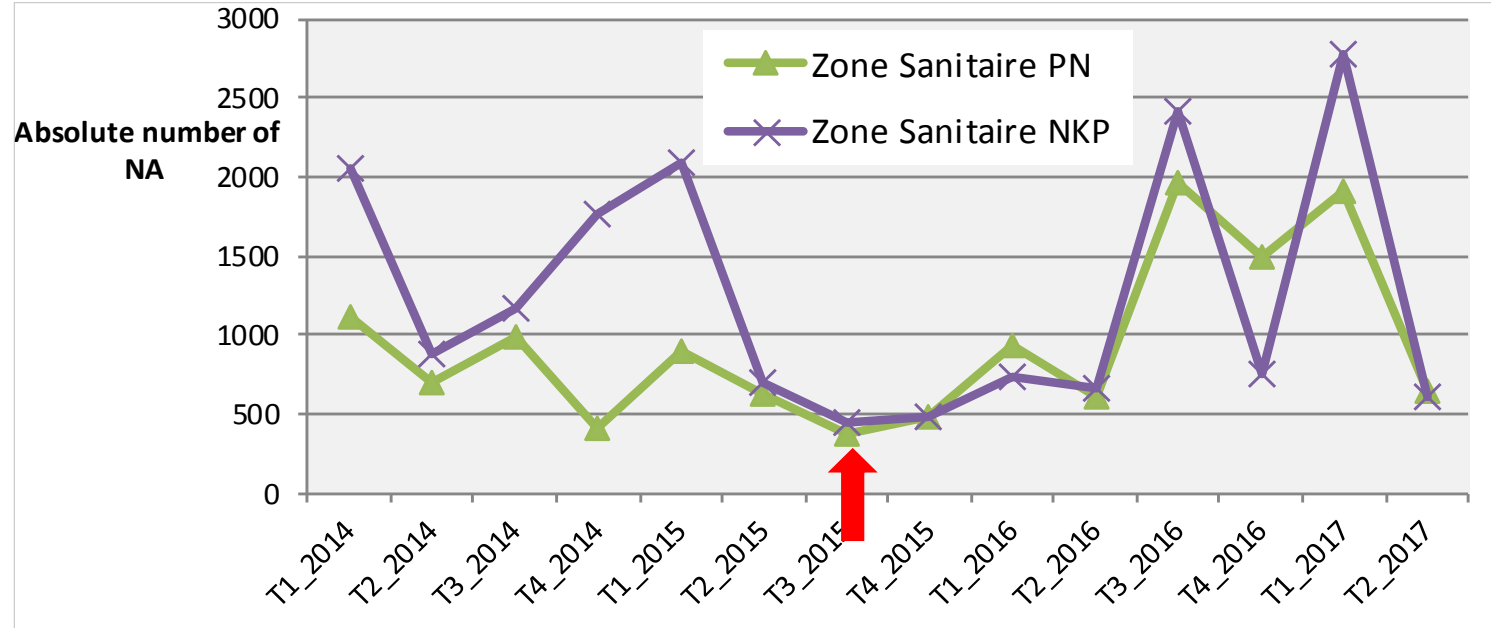

Figure 1. Evolution of new acceptant (NA) for FP all methods combined

Table 2. Evolution of human resources in the Health Facilities of Parakou-N'Dali and Nikki-Kalalé-Pèrèrè health district before and after PBF

\begin{tabular}{|c|c|c|c|c|}
\hline Variables and modalities & $\mathrm{N}$ & $\%$ & PR 95\%CI & p-value \\
\hline Adequacy of qualified personnel according to WHO standards = Yes & & & & \\
\hline - $\quad$ At the end of PBF & 14 & 25.5 & \multirow{2}{*}{$0.88[0.47-1.61]$} & \multirow{2}{*}{0.67} \\
\hline - $\quad$ Before the PBF & 16 & 29.1 & & \\
\hline \multicolumn{5}{|l|}{ Adequacy of midwifery staff according to WHO standards = Yes } \\
\hline - $\quad$ At the end of PBF & 6 & 10.9 & \multirow{2}{*}{$1.2[0.39-3.7]$} & \multirow{2}{*}{0.75} \\
\hline - $\quad$ Before the PBF & 5 & 9.1 & & \\
\hline
\end{tabular}

There is no significant difference in the evolution of either the trained staff $(\mathrm{p}=0.67)$ or the midwifery staff $(\mathrm{p}=0.75)$ before and after PBF.

Table 3. Evolution of the performance, structure and process of Family Planning in Health Facilities of Parakou-N’Dali and Nikki-Kalalé-Pèrèrè health districts before and after PBF

\begin{tabular}{|c|c|c|c|}
\hline \multirow{2}{*}{ Variables } & \multicolumn{2}{|c|}{ Mean \pm standard deviation } & \multirow{2}{*}{ T-test (p value) } \\
\cline { 2 - 3 } & Before PBF & At the end of PBF & $0.063^{*}$ \\
\hline Structure for FP & $0.37 \pm 0.15$ & $0.43 \pm 0.15$ & 0.308 \\
\hline Process for FP & $0.67 \pm 0.22$ & $0.70 \pm 0.21$ & $<0.001^{* * *}$ \\
\hline Performance for FP & $-4.52 \pm 6.83$ & $6.14 \pm 6.62$ & $<$ \\
\hline
\end{tabular}

* p significant at the threshold of $0.10 ; * * *$ p significant at the threshold of 0.001

There is an improvement in family planning structure and performance in the Health Facilities of both districts. For multivariate analyses, we created three variables: the structural evolution (difference between the structure index for Family Planning at the end of PBF and the structure index at the beginning), the evolution of the process (difference between the process index at the end of PBF and the process index at the beginning) and the overall performance in FP (increase rate of new acceptance for Family Planning over the entire study period).

Table 4. Factors associated with PF: standardized beta coefficients in univariate analysis

\begin{tabular}{|c|c|c|c|c|}
\hline Variables & $\mathrm{n}$ & Coefficients Beta standardise & $95 \%$ CI & p value \\
\hline Evolution of the structure & \multirow{2}{*}{55} & 0.294 & {$[0.454-8.135]$} & $0.029 * *$ \\
\cline { 1 - 4 } & \multirow{2}{*}{ Evolution of the process } & 0.238 & {$[-0.428-7.428]$} & $0.080^{*}$ \\
\hline
\end{tabular}

*: p significant at risk of $10 \%$;*: p significant at risk of $5 \%$

Moreover, the correlation analysis between these two variables showed that they are strongly correlated with each other ( $\rho=0.504, p<0.01$ ). For this, in the multivariate model, we retain only the evolution of the structure. 
Table 5. Factors associated with the growth of new acceptance for Family Planning: standardized beta coefficients in multivariate linear regression analysis

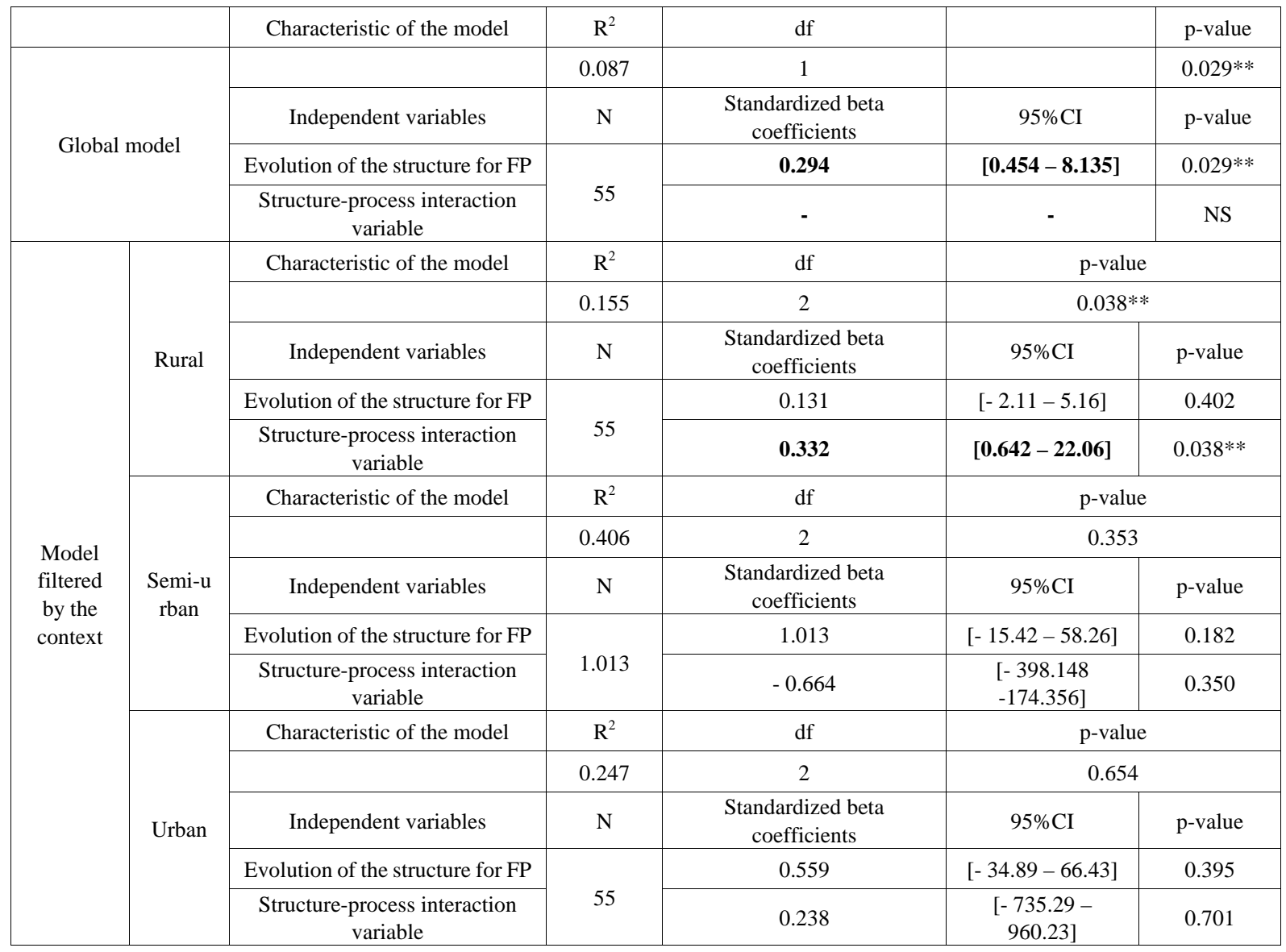

Univariate analysis (Table 4) showed that both structural and process evolution influenced Health Facilities performance. In multivariate analysis (Table 5), overall, the evolution of the structure influenced the performance of the Health Facilities, the interaction variable had no effect.

Using the context variable as a filter, we found that:

- $\quad$ in rural areas, the structure-process interaction had a significant effect on HFs performance in Family Planning;

- in semi-urban and urban areas, the model was not significant and no variable had any effect on HFs performance.

Generally, the evolution of the structure had an impact on HFs performance in FP. But this impact of the evolution of the structure is potentiated, in rural areas, by an adequate evolution of the process of FP services implementation.

\section{Discussion}

This study of PBF's influence on health facilities's performance in Family Planning in Parakou-N'Dali and Nikki-Kalalé-Pèrèrè health districts was based on a longitudinal estimate with repeated experimentation with strong internal validity. However, a number of elements invite us to relativize the scope of our conclusions. First, we had to use secondary PBF data even though they were supplemented as much as possible by data directly collected during the study. Secondly, the study focused mainly on management data without the contribution of health workers or clients for triangulation purposes; these data were collected in the research project but are reserved for later exploitation. Despite these limitations, this study resulted in conclusions that are not without interest. It allows us to focus on three main issues.

Does the PBF have an impact on the improvement of the quality of Family Planning services? Contrary to current studies about the subject, the quality of services in this study has been divided into two sub-components namely the quality of the structure and that of the process. The answer to the question is nuanced: yes there was an overall improvement in the quality of the structure (excluding human resources) but no improvement in the family-planning process in both the two health districts. As Paul et al.[4] stated, the PBF of Benin, World Bank model as that of the Belgian Technical Cooperation did not have a direct effect in terms of improvement of the human resources. This effect on human resources was indirect and concerned the support and ongoing training in the management and monitoring of activities as well as their 
motivation from various sources by the instruments of the PBF (process). But in view of the importance of human resources in the smooth running of Health Facilities activities, it is questionable whether it would have been more appropriate for the State to take the initiative to strengthen staff qualitatively and quantitatively before the beginning of PBF for better achievement of the results of the experiment. The opinion of the interested parties may for this purpose be very instructive.

The overall improvement in the quality of services is found in several studies: Rudasingwa et al. [18] in Burundi on family planning, the overall quality at the midterm evaluation of pilot projects financed by the World Bank in Cameroon and Benin [19].

Does the PBF have an impact on the improvement of Health Facilities's performance in Family Planning services? The answer to this second question is probably yes: there was an improvement in family planning performance in the Health Facilities of the two health districts over the study period. This observation is also in line with that made by Ndikubagenzi et al. [20] in Burundi; these authors found a statistically significant increase in the mean number of FP service users, between pre-scaling and post-scaling up in this country. Similarly, Bonfrer et al. [21] found an improvement in the use of modern family planning services by 5 percentage points $(p=0.002)$. On the contrary, there is no significant impact on clinical productivity in Benin [19] and Eldridge and Palmer [22] did not find, at the end of their review of the literature, clear evidence on the effects of any type of PBF in the health context of any low-income country. These authors have linked this result to the methodological weakness of most studies. Also, according to Blacklock et al.[23] in their systematic review, the impact of PBF on HFs performance in FP is mixed: some studies showed influence, others showed none. These authors rely on the services cost of users to explain this finding. In Benin, since modern Family Planning methods are heavily subsidized, this mechanism seems not to have an influence. Despite Health facilities in Benin PBF model were in majority public ones, their lack of managerial autonomous and not decentralized decision making process, there was a $n$ improvement of their performance in family planning services.

How can we explain the improvement of HFs performance in PF in the background of PBF? Overall, the evolution of the structure was indicative of structure (excluding staff) improvement. But in rural areas, it was the structure-process interaction that was explanatory of the performance; in suburban or urban areas, neither the structure nor the structure-process interaction explained the performance of Health Facilities in Family Planning. This finding in line with Donabedian's work [24] highlights the importance of not using the overall quality of services in the analysis of PBF results but its structure and process components providing a small detail in the analysis of this information, the structure being the set of resources, instruments and technologies necessary for the production of care and the process relating to the application of the best possible procedures for this production. Indeed, in this study, while the structure and its evolution seems correct, the process, which is also related to the structure, poses many more problems.

\section{Implications for Actions}

The first important action to improve the performance of health facilities in the context of PBF should focus on both the structures (staffing) and processes (training, supervision, promotion and monitoring of standards of care). The non-improvement of staff numbers in the health facilities was the assumed choice of PBF experiences in Benin $[2,4]$ which clearly limited the scope of their results in terms of performance. Improving the process was a concern of PBF experiences in Benin; but in view of the increase in the workload that this implies, if there is no concomitant improvement in the number of staff, its effect becomes imperceptible or even nil. The second lesson to be learned from this study is taking into account the context for the previous actions. Indeed, in Benin, as in many sub-Saharan African countries, it is in rural areas that the health system suffers much more from the quantitative and qualitative insufficiency of the staff. The implementation of PBF should take this element into account by adopting any affirmative action policies for HFs in deprived areas. Taking this into account these elements can have a sufficient impact on the overall quality likely to impact the satisfaction of the patients, then the performance in terms of use of health services in Benin.

\section{REFERENCES}

[1] Canavan A., Toonen J., Elovainio R. Performance Based Financing An international review of the literature. Amsterdam: KIT Development Policy \& Practice, December 2008.

[2] Projet de renforcement de la performance du système de santé (PRPSS). Document de cadrage du financement basé sur les résultats (FBR) au Bénin Version validée. Cotonou: Programme de Renforcement de la Performance du Système de Santé, Ministère de la Santé, République du Bénin, 2014.

[3] Projet de renforcement de la performance du système de santé (PRPSS),. Mise à l'échelle du FBR: pari gagné pour le Bénin: Les 34 zones sanitaires couvertes à compter de juin 2015. Bulletin d'Information électronique du Projet de Renforcement de la Performance du Système de Santé, 2015, www.beninfbr.org / www.prss-bj.org (2015).

[4] Paul E., Dramé ML, Kashala JP, et al. Performance-based financing to strengthen the health system in Benin: challenging the mainstream approach. International Journal 
of Health Policy Management 2017; 6: xx-xx.

[5] Hodin Sarah M, Caglia Jacquelyn M, Baye Martina, Bewa Joannie, Waiswa Peter, Ana L. From MDGs to SDGs: Implications for Maternal Newborn Health in Africa. African Journal of Reproductive Health (Special Edition on SDGs) 2016; 20: 26-28.

[6] [6] Cahill Niamh, Sonneveldt Emily, Stover John, Weinberger Michelle, Williamson Jessica, Wei Chuchu. Modern contraceptive use, unmet need, and demand satisfied among women of reproductive age who are married or in a union in the focus countries of the Family Planning 2020 initiative: a systematic analysis using the Family Planning Estimation Tool. The Lancet 2018; 391: 870-882.

[7] République du Bénin, Ministère du Développement de l'Analyse Économique et de la Prospective, Institut National de la Statistique et de l'Analyse Économique I. RGPH4 : que retenir des effectifs de population en 2013? Cotonou: INSAE, Direction des Études Démographiques, July 2015.

[8] Loevinsohn B, Harding A. Buying results? Contracting for health service delivery in developing countries. The Lancet 2005; 676-681.

[9] Toonen J, Canavan A, Vergeer P, et al. Learning lessons on implementing performance based financing from a multi-country evaluation. Amsterdam: KIT Development Policy \& Practice, 2009.

[10] Soeters R, Peerenboom P-B, Mushagalusa P, et al. Performance-Based Financing Experiment Improved Health Care In The Democratic Republic Of Congo. Health Affairs 2011; 30: 1518-1527.

[11] Meessen B, Soucat A, Sekabaraga C. Performance-based financing: just a donor fad or a catalyst towards comprehensive health-care reform? Bulletin of World Health Organization 2011; 153-156.

[12] Soeters R, Habineza C, Peerenboom P-B. Performance-based financing and changing the district health system: experience from Rwanda. Bulletin of the World Health Organization 2006; 84: 884-889.

[13] Oxman A, Fretheim A. Can paying for results help to achieve the Millennium Development Goals?Overview of the effectiveness of results-based financing. Journal of Evidence-Based Medicine 2009; 70-83.

[14] Eichler R, Auxila P, Pollock J. Promoting Preventive Health Care: Paying for Performance in Haiti”, in Contracting for Public Services: Output-Based Aid and its Applications. Volume 21, Washington: The World Bank, 2001.

[15] Meessen B, Musango I, Kashala IJ-P, et al. Performance of rural health centres in Rwanda. Tropical Medicine and International Health 2006; 11: 1303-1317.

[16] Fretheim A, Witter S, Lindahl AK, et al. Performance-based financing in low- and middle-income countries: still more questions than answers. Bulletin of the World Health Organization 2012; 90: 559A.

[17] Oxman A, Fretheim A. An overview of research on the effects of results-based financing (pp. 81(including appendices)). Nasjonalt kunnskapssenter for helsetjenesten
(Norwegian Knowledge Centre for the Health Services). Oslo: John-Arne Røttingen, Director, 2008.

[18] Rudasingwa M, Soeters R, Bossuyt M. The Effect of Performance-Based Financial Incentives on Improving Health Care Provision in Burundi: A Controlled Cohort Study. Global Journal of Health Science 2015; 7: 15-19.

[19] Fonds fiduciaire pour l'innovation en matière de résultats de santé (HRITF). Obtenir des résultats pour la santé des femmes et des enfants. Rapport Intermédiaire, New York: Groupe de la Banque Mondiale, 2015.

[20] Ndikubagenzi J, Nzeyimana E, Gahungere O, Busogoro J-F, Ndayishimiye J-B, N. J. Comparaison de l'utilisation des méthodes contraceptives modernes cinq ans avant et cinq ans après mise à échelle du financement basé sur la performance au Burundi. Bujumbura: Share-Net Burundi, 2017.

[21] Bonfrer Igna, Soeters Robert, van de Poel Ellen, Basenya Olivier, Longin Gashubije, van de Looij Frank, van Doorslaer Eddy. The effects of performance-based financing on the use and quality of health care in Burundi: an impact evaluation. The Lancet 2013; 381: 19.

[22] Eldridge Cynthia, Palmer Natasha. Performance-based payment: some reflections on the discourse, evidence and unanswered questions (REVIEW). Health Policy and Planning 2009; 24: 160-166.

[23] Blacklock Claire, MacPepple Ekelechi, Kunutsor Setor, Sophie W. Paying for Performance to Improve the Delivery and Uptake of Family Planning in Low and Middle Income Countries: A Systematic Review. Studies in Family Planning 2016; 47: 309-324.

[24] Donabedian A. Evaluating the Quality of Medical Care. The Milbank Quarterly 2005; 83: 691-729. 